\title{
Similar progression of diabetic retinopathy with insulin glargine and neutral protamine Hagedorn (NPH) insulin in patients with type 2 diabetes: a long-term, randomised, open-label study
}

\author{
J. Rosenstock • V. Fonseca • J. B. McGill • M. Riddle • \\ J.-P. Hallé • I. Hramiak • P. Johnston • M. Davis
}

Received: 26 November 2008 / Accepted: 5 May 2009 /Published online: 13 June 2009

(C) The Author(s) 2009. This article is published with open access at Springerlink.com

\begin{abstract}
Aims/hypothesis This long-term study was designed to further characterise the retinal safety profile of insulin glargine and human neutral protamine Hagedorn (NPH) insulin in patients with type 2 diabetes mellitus.

Methods An open-label, 5 year, randomised (1:1), multicentre, stratified, parallel-group study conducted in the USA and Canada enrolled individuals with type 2 diabetes and either no or non-proliferative retinopathy (less than severe; Early Treatment Diabetic Retinopathy Study [ETDRS] level less than 53 in both eyes) who were treated with oral hypoglycaemic agents (OHAs) alone, insulin alone or OHAs with insulin for $\geq 3$ months prior to study
\end{abstract}

Electronic supplementary material The online version of this article (doi:10.1007/s00125-009-1415-7) contains supplementary material, which is available to authorised users.

J. Rosenstock $(\bowtie)$

Dallas Diabetes and Endocrine Center at Medical City,

7777 Forest Lane C-685,

Dallas, TX 75230, USA

e-mail: juliorosenstock@dallasdiabetes.com

J. Rosenstock

University of Texas Southwestern Medical School,

Dallas, TX, USA

\section{Fonseca}

Tulane University Medical Center,

New Orleans, LA, USA

J. B. McGill

Washington University School of Medicine,

St Louis, MO, USA

\section{Riddle}

Oregon Health and Science University,

Portland, OR, USA entry and a baseline $\mathrm{HbA}_{1 \mathrm{c}}$ level of $6.0-12.0 \%$. Patients were randomised by the investigator according to the centralised interactive voice response system to receive twice-daily NPH insulin $(n=509)$ or once-daily basal insulin glargine $(n=515)$. The investigator was not blinded to the treatment group to which each participant had been assigned. The main objective of this study was to compare the progression of diabetic retinopathy between treatment groups by analysing the percentage of patients with three or more step progression in the ETDRS retinopathy patientlevel severity scale after treatment with either basal insulin. Masked, centralised grading of seven-field stereoscopic fundus photographs was used.

J.-P. Hallé

Université de Montréal,

Montréal, QC, Canada

I. Hramiak

University of Western Ontario,

London, ON, Canada

P. Johnston

sanofi-aventis,

Bridgewater, NJ, USA

M. Davis

University of Wisconsin School of Medicine and Public Health, Madison, WI, USA 
Results Similarly sustained glycaemic control was observed in both the insulin glargine and NPH insulin treatment groups. Despite a slightly greater severity of diabetic retinopathy for the insulin glargine group at baseline, three or more step progression in ETDRS score from baseline to end-of-study was similar between treatment groups $(14.2 \%$ [53/374] of insulin glargine-treated patients vs $15.7 \%[57 /$ 363] of NPH-treated patients); the difference in the incidence of progression was $-1.98 \%$ (95\% CI -7.02 , $3.06 \%$ ). Other measures of retinopathy - the development of proliferative diabetic retinopathy and progression to clinically significant macular oedema-occurred to a similar degree in both treatment groups. No other safety issues, such as unexpected adverse events for either insulin emerged during the 5 year study. However, NPH insulin treatment was associated with a higher incidence of severe hypoglycaemia compared with insulin glargine.

Conclusions/interpretation This study shows no evidence of a greater risk of the development or progression of diabetic retinopathy with insulin glargine vs NPH insulin treatment in patients with type 2 diabetes mellitus.

Trial registration ClinicalTrials.gov NCT00174824

Funding This study was sponsored by sanofi-aventis.

Keywords CSME · ETDRS · Insulin action ·

Insulin glargine $\cdot$ Insulin therapy $\cdot \mathrm{NPH}$ insulin .

Retinopathy · Type 2 diabetes

$\begin{array}{ll}\text { Abbreviations } \\ \text { ETDRS } & \text { Early Treatment Diabetic Retinopathy Study } \\ \text { FPG } & \text { Fasting plasma glucose } \\ \text { ITT } & \text { Intention-to-treat } \\ \text { LS } & \text { Least square } \\ \text { NPH } & \text { Neutral protamine Hagedorn } \\ \text { OHA } & \text { Oral hypoglycaemic agent } \\ \text { PP } & \text { Per protocol } \\ \text { UKPDS } & \text { UK Prospective Diabetes Study }\end{array}$

\section{Introduction}

Clinical trials in patients with type 1 and type 2 diabetes mellitus have established that maintenance of nearnormoglycaemic control reduces the risk of microvascular complications, such as diabetic retinopathy [1-5]. To facilitate reaching glycaemic goals without excessive hypoglycaemia, analogues of human insulin with improved pharmacokinetic and pharmacodynamic action profiles have been developed [6-9].

Insulin glargine (A21Gly,B31Arg,B32Arg human insulin) is a recombinant, long-acting basal insulin analogue that differs from human insulin by the substitution of glycine for asparagine at position 21 of the $\mathrm{A}$ chain and the addition of two arginines at the $\mathrm{C}$-terminus of the $\mathrm{B}$ chain. These changes produce an insulin with a duration of action of approximately $24 \mathrm{~h}$ or more after subcutaneous injection, without pronounced peaks of activity [10]. In clinical trials, a single daily injection of insulin glargine provides glycaemic control equivalent to that afforded by neutral protamine Hagedorn (NPH) insulin [11-15], but with a lower risk of hypoglycaemia [16, 17].

One of the five 6 month, phase 3 registration trials of insulin glargine [14] reported that the percentage of participants with an increase of three or more steps on the Early Treatment Diabetic Retinopathy Study (ETDRS) retinopathy severity scale was greater in the insulin glargine group $(7.0 \%)$ than in the human NPH insulin group $(2.7 \%)$. This finding may have been related to chance or to differences at baseline in the patients studied, especially since no retinopathy entrance criteria were specified and the data showed more of a 'scatter' and did not follow a natural progression [18]. However, because of the potential importance of this finding, a carefully designed clinical trial of sufficient duration and statistical power was conducted to address the long-term safety of insulin glargine compared with human NPH insulin. Here we report the findings of this trial, which used change on the ETDRS scale based on the masked, centralised grading of seven-field stereoscopic fundus photographs as the primary measure of retinopathy progression in patients with type 2 diabetes mellitus [19].

\section{Methods}

Study design This was a 5 year, multicentre, multinational (USA and Canada), randomised (1:1), open-label, human NPH insulin-controlled, parallel-group study in patients with type 2 diabetes mellitus suited to treatment with a basal insulin. The study recruited male or female type 2 diabetes mellitus patients, aged 30-70 years, with a diagnosis of type 2 diabetes mellitus for $\geq 1$ year, treated with oral hypoglycaemic agents (OHAs), or insulin alone or in combination, for $\geq 1$ year prior to screening, with a stable dose(s) for $\geq 3$ months prior to screening. $\mathrm{HbA}_{1 \mathrm{c}}$ was required to be $6.0-12.0 \%$ at screening. Exclusion criteria included the presence of proliferative or severe non-proliferative diabetic retinopathy (ETDRS level 53 or greater in either eye); laser photocoagulation or vitrectomy prior to study entry; use of any insulin analogues $\leq 3$ months prior to screening; systolic blood pressure $>150 \mathrm{mmHg}$ or diastolic blood pressure $>95 \mathrm{mmHg}$ at screening; and a history of hypoglycaemia unawareness (more than two severe hypoglycaemia episodes without warning in the past year). The study was conducted in accordance with the Declaration of Helsinki, and approval by institutional ethics committees was 
obtained for each participating site. All patients provided written informed consent prior to study entry.

Study treatment Before randomisation, eligible patients were stratified on a $1: 1$ basis by baseline $\mathrm{HbA}_{1 \mathrm{c}}$ level $(6.0-9.0 \%$ and $>9.0-12.0 \%)$ to ensure that the patients in each $\mathrm{HbA}_{1 \mathrm{c}}$ category were distributed equally between the two treatment groups. Following randomisation, patients received open-label insulin glargine once daily, generally at bedtime, or NPH insulin twice daily, generally in the morning and at bedtime.

In both groups, insulin doses were titrated over the first 3 years of the study, with the aim of achieving fasting plasma glucose (FPG) levels of $\leq 6.7 \mathrm{mmol} / 1(\leq 120 \mathrm{mg} / \mathrm{dl})$. This target was reduced to $\leq 5.5 \mathrm{mmol} / 1(\leq 100 \mathrm{mg} / \mathrm{dl})$ for the last 2 years of the study. Whilst attempting to reach these glycaemic goals, OHAs and/or prandial insulin doses taken at baseline could be continued or modified during the trial, and human regular insulin could be added with meals even if not used at baseline, at the investigator's discretion. However, no specific titration guidelines for pre-meal regular insulin dosing were provided.

Outcome and safety measures The primary objective of this study was to compare the percentage of patients with three or more step progression in ETDRS score after 5 years of treatment with either insulin glargine or NPH insulin. The secondary efficacy assessments included the percentage of patients with three or more step progression in ETDRS score after 3, 6, 12, 24, 36, 48 and 60 months of treatment; the percentage of patients who developed proliferative diabetic retinopathy; the distribution of change on the ETDRS scale; the percentage of patients who developed clinically significant macular oedema; the change from baseline in overall $\mathrm{HbA}_{1 \mathrm{c}}$ and FPG levels; the overall incidence and rate of symptomatic hypoglycaemia (all episodes of symptomatic hypoglycaemia), symptomatic nocturnal hypoglycaemia and severe hypoglycaemia (symptomatic hypoglycaemia requiring assistance and either with blood glucose levels of $\leq 3.1 \mathrm{mmol} / \mathrm{l}$ or treated with oral or injectable carbohydrate or glucagon injection); and insulin doses. Weight, blood pressure (recorded in the seated position), $\mathrm{HbA}_{\mathrm{lc}}$ (performed by the Diabetes Diagnostic Laboratories, Columbia, MO, USA, using the National Glycohemoglobin Standardization Programme [level 1]) [5] and FPG (performed locally for each site by laboratories that were required to be Clinical Laboratory Improvement Amendment-certified) were measured every 3 months. Patients were provided the Accu-Chek blood glucose meter (Roche Diagnostics, Indianapolis, IN, USA) and instructed on how to use it during the screening phase; they were asked to measure blood glucose at least twice a day.

Diabetic retinopathy status was assessed in seven-field stereoscopic fundus photographs obtained at screening and after 3, 6, 12, 24, 36, 48 and 60 months of treatment [19-21]. Photographs underwent treatment-group-masked grading, without comparison with other photographs, at the University of Wisconsin Fundus Photograph Reading Centre (FPRC). To verify progression status, a side-by-side comparison of baseline and follow-up photographs masked to treatment was conducted by a senior grader for any patient whose ETDRS score demonstrated a three step or greater progression over baseline at any time point during the study.

Safety was assessed by the evaluation of reported adverse events using the Medical Dictionary for Regulatory Activities (MedDRA) coding (Version 10.0; MSSO, Chantilly, VA, USA). Additional safety assessments were severe hypoglycaemia; physical examinations, including periodic funduscopic examinations; vital signs (seated) and body weight; laboratory serum creatinine and lipoprotein levels were performed by Covance Central Laboratory Services (Covance CLS, Indianapolis, IN, USA) using the Roche Modular Analyzer (Roche Diagnostics, Manheim, Germany).

Statistical methods Sample size was calculated assuming a $20 \% 5$ year event rate for a three or more step progression in diabetic retinopathy on the ETDRS scale from baseline to end of study (based on data from the DCCT [22]), and a non-inferiority margin of $10 \%$ (half of the expected background rate of 20\%) was chosen. Assuming that approximately $40 \%$ of the randomised patients would not be evaluable, a sample size of 840 randomised patients $(420$ per treatment group) was calculated to provide at least $80 \%$ power for declaring non-inferiority.

The per protocol (PP) population consisted of patients who had undergone at least 4 years of treatment (not necessarily consecutively) with the study drug and who had evaluable fundus photographs taken at least 4.5 years after starting study medication, or who had three or more step progression of retinopathy on the ETDRS scale. The PP population was the primary analysis population for the primary outcome endpoint. An intention-to-treat (ITT) population (all randomised patients who received at least one dose of study medication) was used to confirm the PP primary analyses and was the population used for all secondary analyses. However, as many clinical trials use the ITT population for the primary analysis, in this paper we initially present the ITT population results followed by the PP population analysis.

The primary efficacy analysis was conducted using a generalised linear model (generated by the statistics software SAS GENMOD, Version 8 [SAS, Cary, NC, USA]) with the response of three step or greater progression in the ETDRS from baseline to endpoint as the dependent variable, treatment and baseline $\mathrm{HbA}_{1 \mathrm{c}}$ strata as the classified independent variables, and with binomial distribution and identity link function. The $95 \%$ CIs were 
derived from least square (LS) mean results. A stepwise closed testing approach was used for the primary efficacy analysis. First, non-inferiority was demonstrated if the upper bound of the $95 \%$ CI for the treatment difference in the participants with a three step or greater progression in the ETDRS from baseline to endpoint between insulin glargine and NPH insulin in the PP population was $\leq 10 \%$. Second, non-inferiority and superiority (upper bound of $95 \%$ CI $<0.0 \%$ ) were tested in the ITT population. The overall $\alpha$ level for significance was 0.05 .

\section{Results}

Patient demographics and baseline characteristics Figure 1 shows the disposition of study participants. Patients in the two treatment groups were generally similar in terms of baseline characteristics (Table 1). The majority of participants had previously been treated with OHAs, and $69 \%$ had been treated with insulin for an average of 5 years prior to study entry. The mean duration of prior insulin use, percentage of participants with a history of diabetic retinopathy, and the percentage of participants with diabetic retinopathy of moderate non-proliferative severity or worse (ETDRS level 43 or greater in either eye) by photograph grading were all slightly greater at baseline for the insulin glargine group than for the NPH insulin group. More participants in the insulin glargine group than in the NPH insulin group had Grade C macular oedema at baseline. Mean systolic and diastolic blood pressures were comparable in the two treatment groups; $60.4 \%$ and $60.9 \%$ of patients randomised to the insulin glargine and NPH insulin groups, respectively, had hypertension at baseline.

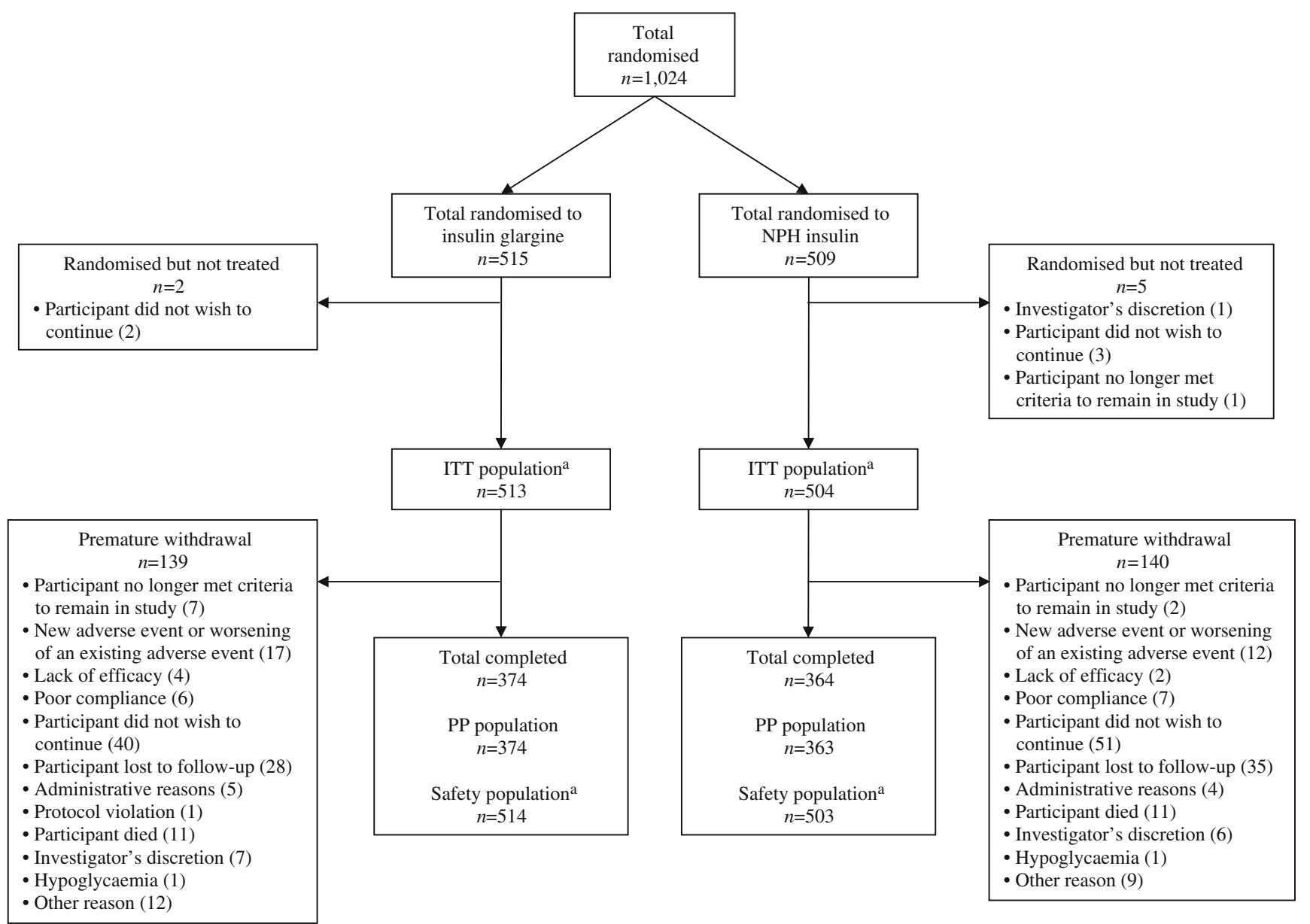

Fig. 1 Summary of participant randomisation and disposition. This study was conducted between June 2001 and April 2007. Patients entering the screening phase $(1,413$ participants were screened at 46 sites in the USA and 16 sites in Canada) received a participant number and, following fulfilment of inclusion criteria (at the end of the screening phase), were randomised by the investigator according to the centralised interactive voice response system (IVRS). The randomisation schedule $(1: 1)$ was stratified by investigational centre

and baseline $\mathrm{HbA}_{1 \mathrm{c}}$ levels $(6.0-9.0 \%$ and $>9.0-12.0 \%)$. The investigator was not blinded to the treatment group to which each participant had been assigned. ${ }^{a}$ One patient who was randomised to receive NPH insulin received insulin glargine throughout the study, and is consequently counted in the ITT population as an NPH patient, but in the safety population as an insulin glargine patient, leading to a discrepancy in the numbers for the ITT and safety populations in both the insulin glargine and NPH insulin arms 
Table 1 Patient demographics and baseline characteristics
Data are mean \pm SD unless otherwise stated; all values refer to the ITT population unless otherwise stated

${ }^{a}$ Eyes without microaneurysms but with retinal haemorrhages or exudates were included here

${ }^{\mathrm{b}} \mathrm{PP}$ population, consisting of 374 participants in the insulin glargine group; 363 participants in the NPH insulin group. Level A, no macular oedema; Level B, macular oedema present but not clinically significant; Level C, CSMO but centre of macula not involved; Level D, CSMO with centre of macula involved

DR, diabetic retinopathy;

NPDR, non-proliferative diabetic retinopathy; CSMO, clinically significant macular oedema

\begin{tabular}{|c|c|c|}
\hline Variable & Insulin glargine $(n=513)$ & NPH insulin $(n=504)$ \\
\hline Age, years & $54.9 \pm 8.8$ & $55.3 \pm 8.5$ \\
\hline \multicolumn{3}{|l|}{ Age category, $n(\%)$} \\
\hline$<65$ years & $429(83.6)$ & $427(84.7)$ \\
\hline $65-75$ years & $84(16.4)$ & $77(15.3)$ \\
\hline \multicolumn{3}{|l|}{ Sex, $n(\%)$} \\
\hline Male & $278(54.2)$ & $270(53.6)$ \\
\hline Female & $235(45.8)$ & $234(46.4)$ \\
\hline Weight, kg & $100.2 \pm 22.7$ & $98.7 \pm 22.3$ \\
\hline Height, cm & $170.1 \pm 10.1$ & $170.1 \pm 10.3$ \\
\hline BMI, $\mathrm{kg} / \mathrm{m}^{2}$ & $34.5 \pm 7.2$ & $34.1 \pm 7.2$ \\
\hline Duration of diabetes, years & $10.7 \pm 6.9$ & $10.8 \pm 6.7$ \\
\hline $\mathrm{HbA}_{1 \mathrm{c}}, \%$ & $8.41 \pm 1.38$ & $8.31 \pm 1.38$ \\
\hline FPG, mmol/1 & $10.5 \pm 3.7$ & $10.0 \pm 3.4$ \\
\hline Previous glucose-lowering treatment, $n(\%)$ & $513(100)$ & $504(100)$ \\
\hline Prior treatment with $\mathrm{OHA}, n$ & 494 & 476 \\
\hline Duration, years & $9.0 \pm 6.3$ & $8.9 \pm 5.7$ \\
\hline Prior treatment with insulin, $n$ & 344 & 354 \\
\hline Duration, years & $5.5 \pm 6.0$ & $4.9 \pm 5.1$ \\
\hline \multicolumn{3}{|l|}{ Diabetic late complications, $n(\%)$} \\
\hline Total & $308(60.0)$ & $291(57.7)$ \\
\hline Diabetic retinopathy & $80(15.6)$ & $61(12.1)$ \\
\hline Diabetic nephropathy & $60(11.7)$ & $48(9.5)$ \\
\hline Diabetic neuropathy & $245(47.8)$ & $241(47.8)$ \\
\hline Diabetic macroangiopathy & $64(12.5)$ & $67(13.3)$ \\
\hline Blood pressure, $n$ & 514 & 503 \\
\hline Systolic blood pressure, $\mathrm{mmHg}$ & $131.5 \pm 14.9$ & $130.5 \pm 13.8$ \\
\hline Diastolic blood pressure, $\mathrm{mmHg}$ & $77.3 \pm 9.1$ & $76.9 \pm 9.0$ \\
\hline \multicolumn{3}{|l|}{ Baseline ETDRS retinopathy severity, $n(\%)$} \\
\hline No DR & $198(38.6)$ & $196(38.9)$ \\
\hline Microaneurysms only, one eye $\mathrm{a}^{\mathrm{a}}$ & $73(14.2)$ & $83(16.5)$ \\
\hline Microaneurysms only, both eyes ${ }^{\mathrm{a}}$ & $43(8.4)$ & $44(8.7)$ \\
\hline Mild NPDR (level $35 /<35$ or $35 / 35$ ) & $146(28.5)$ & $142(28.2)$ \\
\hline Moderate NPDR or worse (level $43 /<43$ or worse) & $53(10.3)$ & $39(7.7)$ \\
\hline Modified CSMO score ${ }^{\mathrm{b}}, n(\%)$ & 374 & 363 \\
\hline \multicolumn{3}{|l|}{ Right eye } \\
\hline Level A & $352(94.1)$ & $352(97.0)$ \\
\hline Level B & $12(3.2)$ & $7(1.9)$ \\
\hline Level C & $7(1.9)$ & $1(0.3)$ \\
\hline Level D & $3(0.8)$ & $2(0.6)$ \\
\hline \multicolumn{3}{|l|}{ Left eye } \\
\hline Level A & $355(94.9)$ & $347(95.6)$ \\
\hline Level B & $7(1.9)$ & $12(3.3)$ \\
\hline Level C & $10(2.7)$ & 0 \\
\hline Level D & $2(0.5)$ & $3(0.8)$ \\
\hline Missing & 0 & $1(0.3)$ \\
\hline
\end{tabular}

$F P G, H b A_{1 c}$, insulin dose and hypoglycaemia Figure 2 shows the metabolic changes over time in the two treatment arms. Overall, FPG declined in both treatment groups early in the study, and then reached a plateau until endpoint
(Fig. 2a). In the insulin glargine group, this decline was from a mean baseline level of $10.6 \pm 3.7 \mathrm{mmol} / 1$ to a mean endpoint level of $7.8 \pm 3.2 \mathrm{mmol} / \mathrm{l}$; in the $\mathrm{NPH}$ insulin group, FPG decreased from a mean of $10.0 \pm 3.4 \mathrm{mmol} / \mathrm{l}$ to 
a mean of $7.7 \pm 3.2 \mathrm{mmol} / 1$ (ITT population). Insulin glargine treatment increased the percentage of patients achieving the target FPG ( $\leq 5.6 \mathrm{mmol} / \mathrm{l})$ from $6.4 \%$ at baseline to $28.5 \%$ at endpoint; NPH insulin treatment caused an increase from $7.7 \%$ to $24.3 \%$.

Mean $\mathrm{HbA}_{1 \mathrm{c}}$ in the ITT population declined in both groups during the first 6 months of the study and remained similarly stable thereafter (Fig. 2b). At study end, mean $\mathrm{HbA}_{1 \mathrm{c}}$ (last observation carried forward) improved from a baseline of $8.4 \%$ and $8.3 \%$ to $7.8 \%$ and $7.6 \%$ for all patients in the insulin glargine and NPH insulin groups, respectively (Table 2). The mean $\mathrm{HbA}_{1 \mathrm{c}}$ change from baseline was $-0.55 \%$ with insulin glargine and $-0.76 \%$ with NPH insulin (LS mean difference 0.21 more with NPH insulin, $95 \%$ CI $0.06-0.35 ; p=0.0053$ ). An exploratory post hoc analysis of the subgroup of patients who were taking basal insulin with OHAs, but no regular insulin, which included 168 and 155 insulin glargine-treated and NPH insulin-treated patients, respectively, showed that mean $\mathrm{HbA}_{1 \mathrm{c}}$ values were equivalent between treatment groups throughout the study (Fig. 2c).

The mean basal insulin dose at endpoint was lower for insulin glargine than for NPH insulin $(62 \pm 39$ and $72 \pm 48 \mathrm{IU}$, respectively; Table 2). The daily dose of prandial insulin administered at the end of the study was $44 \pm 42$ and $32 \pm 38$ IU for insulin glargine and NPH insulin, respectively, for the subset of patients taking prandial insulin. The mean daily total insulin doses (basal plus prandial insulin) by the endpoint of the study were $89 \pm 66$ IU for the insulin glargine group and $92 \pm 66 \mathrm{IU}$ for the NPH insulin group.

Frequencies of the three defined categories of hypoglycaemia in this study are shown in Table 2. NPH insulin treatment was associated with a greater incidence of severe hypoglycaemia than was insulin glargine (11.1\% [55/494] vs $7.6 \%$ [38/501], respectively; $p=0.0439$ ). Analysis of the yearly rate rather than the patient incidence revealed that there was a significant difference between the two groups with respect to symptomatic hypoglycaemia (mean yearly rate of $7.08 \pm 16.49$ with NPH insulin vs $5.13 \pm 12.79$ with insulin glargine; $p=0.0017$; Table 2; Fig. 2d).

Fig. 2 Metabolic changes (mean \pm SD) during the course of the study from baseline to endpoint (last observation carried forward) in the insulin glargine and NPH insulin groups. a Change in FPG levels over time with twice-daily NPH insulin (squares) and once-daily insulin glargine (triangles; ITT population). b Change in $\mathrm{HbA}_{1 \mathrm{c}}$ levels over time with twice-daily NPH insulin (squares) and once-daily insulin glargine (triangles; ITT population). c Change in $\mathrm{HbA}_{1 \mathrm{c}}$ levels over time with twice-daily NPH insulin (squares) and once-daily insulin glargine (triangles) in patients treated with basal insulin plus OHAs only (ITT population). d Summary of patient mean yearly rate of hypoglycaemia with twice-daily NPH insulin (black bars) and oncedaily insulin glargine (white bars) (ITT population). Yearly rate of hypoglycaemia was calculated by $365.25 \times$ (number of episodes in the period)/(number of days in period)
Retinopathy progression The ITT analysis showed a difference of $-2.10 \%$ (95\% CI $-6.29 \%, 2.09 \%)$ between the two treatment arms in the proportion of patients with three or more step progression (ETDRS scale), the proportion being lower for insulin glargine (Table 3). As the upper bound of the $95 \%$ CI was $>0$ in the ITT analysis, superiority of
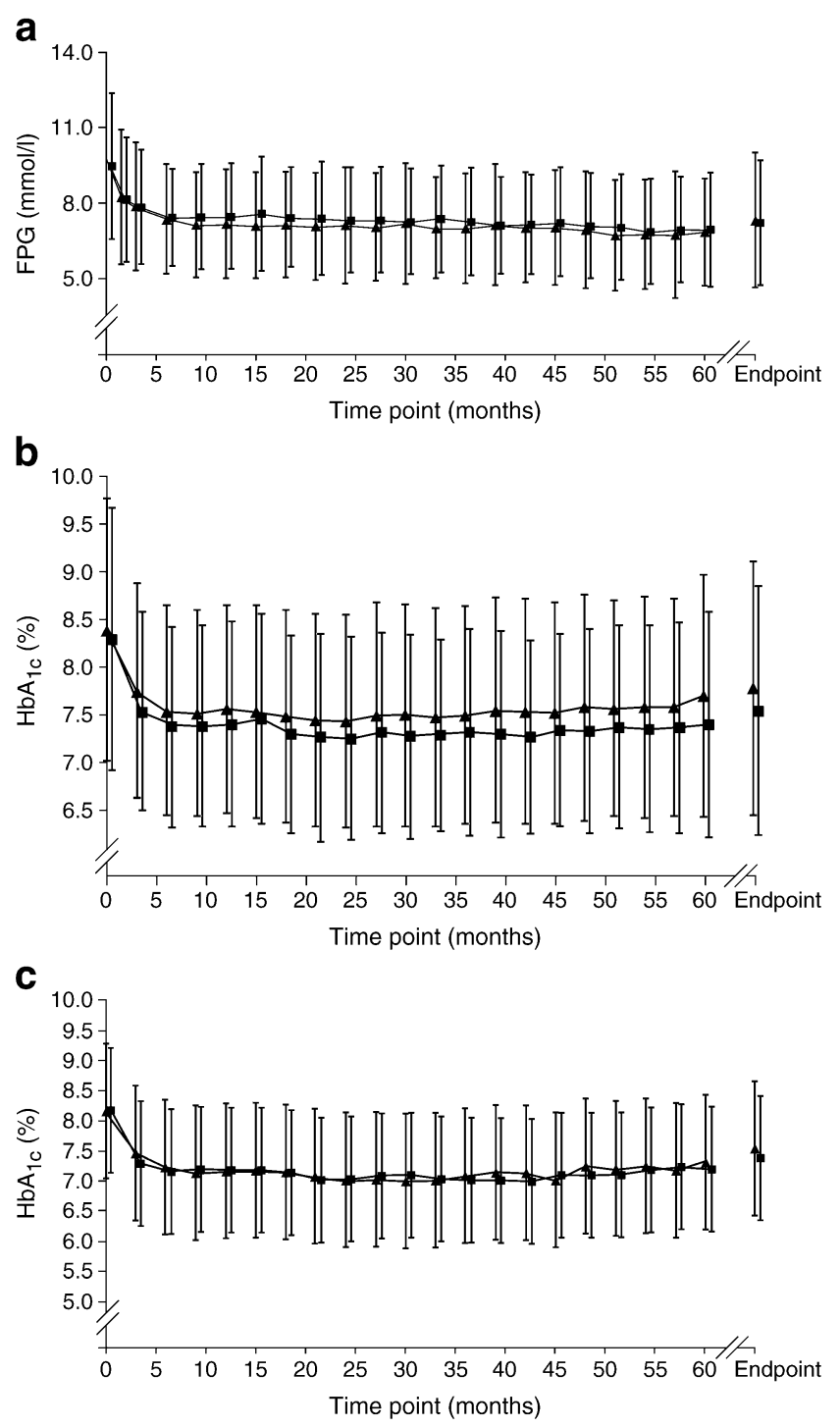

d

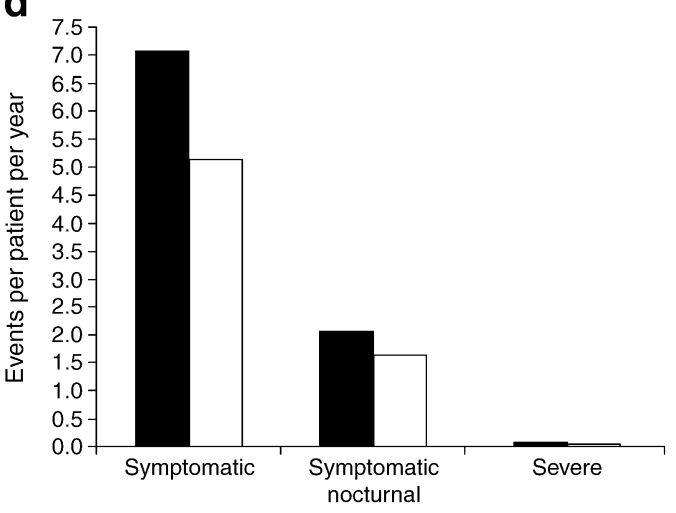


Table 2 Summary of the metabolic efficacy results (ITT population)

\begin{tabular}{|c|c|c|c|c|c|}
\hline Variable & $\begin{array}{l}\text { Insulin glargine } \\
(n=513)\end{array}$ & $\begin{array}{l}\text { NPH insulin } \\
(n=504)\end{array}$ & $\begin{array}{l}\text { Difference between } \\
\text { groups, LS mean } \pm \text { SEM }\end{array}$ & $95 \% \mathrm{CI}$ & $p$ value \\
\hline $\mathrm{HbA}_{1 \mathrm{c}}$ at endpoint (\%) & $7.80 \pm 1.33$ & $7.56 \pm 1.31$ & & & \\
\hline Change from baseline & $-0.55 \pm 0.06$ & $-0.76 \pm 0.06$ & $0.21 \pm 0.07$ & $0.06,0.35$ & 0.0053 \\
\hline FPG at endpoint (mmol/l) & $7.8 \pm 3.2$ & $7.7 \pm 3.2$ & & & \\
\hline Change from baseline & $-2.5 \pm 0.2$ & $-2.5 \pm 0.2$ & $-0.04 \pm 0.2$ & $-0.4,0.4$ & 0.8414 \\
\hline Weight at endpoint (kg) & $103.2 \pm 24.5$ & $103.0 \pm 23.7$ & & & \\
\hline Change from baseline & $3.7 \pm 0.46$ & $4.8 \pm 0.46$ & $-1.2 \pm 0.60$ & $-2.34,0.00$ & 0.0505 \\
\hline $\begin{array}{l}\text { Basal daily insulin dose } \\
\text { at endpoint (IU) }\end{array}$ & $61.84 \pm 39.41$ & $72.31 \pm 47.52$ & & & \\
\hline $\begin{array}{l}\text { Prandial daily insulin dose } \\
\text { at endpoint (IU) }\end{array}$ & $43.83 \pm 41.62$ & $31.81 \pm 37.68$ & & & \\
\hline $\begin{array}{l}\text { Daily insulin dose at endpoint } \\
\text { (basal plus prandial) (IU) }\end{array}$ & $88.59 \pm 65.92$ & $91.80 \pm 66.36$ & $-3.16 \pm 4.12$ & $-11.24,4.93$ & 0.4438 \\
\hline \multicolumn{6}{|l|}{ Patients with hypoglycaemic events ${ }^{\mathrm{a}}$} \\
\hline Symptomatic hypoglycaemia & $370(73.9)$ & 385 (77.9) & & & 0.1366 \\
\hline Symptomatic nocturnal hypoglycaemia & $281(56.1)$ & $296(59.9)$ & & & 0.2248 \\
\hline Severe hypoglycaemia & $38(7.6)$ & $55(11.1)$ & & & 0.0439 \\
\hline \multicolumn{6}{|l|}{ Patients' mean yearly rate of hypoglycaemia ${ }^{a}$} \\
\hline Symptomatic hypoglycaemia & $5.13 \pm 12.79$ & $7.08 \pm 16.49$ & & & 0.0017 \\
\hline Symptomatic nocturnal hypoglycaemia & $1.66 \pm 4.25$ & $2.11 \pm 4.88$ & & & 0.0705 \\
\hline Severe hypoglycaemia & $0.04 \pm 0.23$ & $0.06 \pm 0.30$ & & & 0.0563 \\
\hline
\end{tabular}

Data are mean $\pm \mathrm{SD}$ or $n(\%)$ unless otherwise stated. The $95 \%$ CIs were calculated for the LS mean difference

${ }^{a}$ From month 3 to endpoint. Number of participants included in analysis: 501 and 494 in the insulin glargine and NPH insulin groups, respectively

Table 3 Summary of the retinal efficacy results (ITT and PP populations)

\begin{tabular}{|c|c|c|c|c|c|}
\hline \multirow[t]{2}{*}{ Subgroup } & \multicolumn{2}{|l|}{$n / N^{\mathrm{a}}(\%)$} & \multirow[t]{2}{*}{ Difference between groups, LS mean \pm SEM } & \multirow[t]{2}{*}{$95 \% \mathrm{CI}$} & \multirow[t]{2}{*}{$p$ value } \\
\hline & Insulin glargine & $\mathrm{NPH}$ insulin & & & \\
\hline \multicolumn{6}{|c|}{ Patients with $\geq 3$ step progression in ETDRS score at endpoint } \\
\hline ITT & $63 / 502(12.5)$ & $71 / 487(14.6)$ & $-2.10 \pm 2.14$ & $-6.29,2.09$ & $-{ }^{b}$ \\
\hline PP & $53 / 374(14.2)$ & $57 / 363(15.7)$ & $-1.98 \pm 2.57$ & $-7.02,3.06$ & $-{ }^{\mathrm{b}}$ \\
\hline \multicolumn{6}{|c|}{ Patients developing PDR during the study } \\
\hline ITT & $25 / 496(5.0)$ & $16 / 483(3.3)$ & - & - & 0.2095 \\
\hline $\mathrm{PP}$ & $20 / 373(5.4)$ & $14 / 363(3.9)$ & - & - & 0.5064 \\
\hline \multicolumn{6}{|c|}{ Patients developing $\mathrm{CSMO}^{\mathrm{c}}$ during the study } \\
\hline ITT & 68/493 (13.8) & 68/481 (14.1) & - & - & 0.8818 \\
\hline PP & $58 / 371(15.6)$ & $53 / 362(14.6)$ & - & - & 0.7674 \\
\hline
\end{tabular}

Results are $n(\%)$ unless otherwise stated, as appropriate for the ITT or PP populations. The $95 \%$ CIs were calculated for the LS mean difference

${ }^{a} / N$, number/total number analysed

${ }^{\mathrm{b}}$ Confidence intervals rather than $p$ values were used to assess the primary outcome in this non-inferiority trial

${ }^{c}$ Any eye was considered to have developed clinically significant macular oedema (CSMO) if the eye's modified CSMO score increased to level C or D from level A or B at baseline, at any time during the trial, or if an eye at level A or B at baseline had undergone focal/grid photocoagulation at any time during the trial. For a description of the different CSMO levels, see the footnotes to Table 1 . An eye was excluded from the analysis if it had previous focal/grid photocoagulation at baseline. A patient was considered to have developed CSMO if either or both eyes had developed CSMO

PDR, proliferative diabetic retinopathy 
insulin glargine over NPH insulin was not demonstrated. At endpoint in approximately $14 \%$ of patients in each treatment group, retinopathy had progressed by three or more steps. There were no differences between treatments in the proportion of patients with three or more step progression in ETDRS score at endpoint in either of the two randomised $\mathrm{HbA}_{1 \mathrm{c}}$ strata (6.0-9.0\% and >9.0-12.0\%).

The primary analysis population for retinopathy progression was, however, the PP population, and Fig. 3 shows the incidence of progression of retinopathy compared with baseline at various stages of treatment in these patients. At the end of 1 year of treatment, three or more step progression in ETDRS score was observed in $4.6 \%$ and $5.8 \%$ of insulin glargine-treated and NPH insulin-treated participants, respectively (Fig. 3a). The frequency of patients showing three or more step ETDRS progression continued to increase in year $2(8.1 \%$ vs $9.4 \%$ in the insulin glargine and NPH insulin groups); Fig. 3a presents the incidence of progression over time for both treatment groups. At endpoint, 14.2\% (53/374) of insulin glargine-

\section{a}

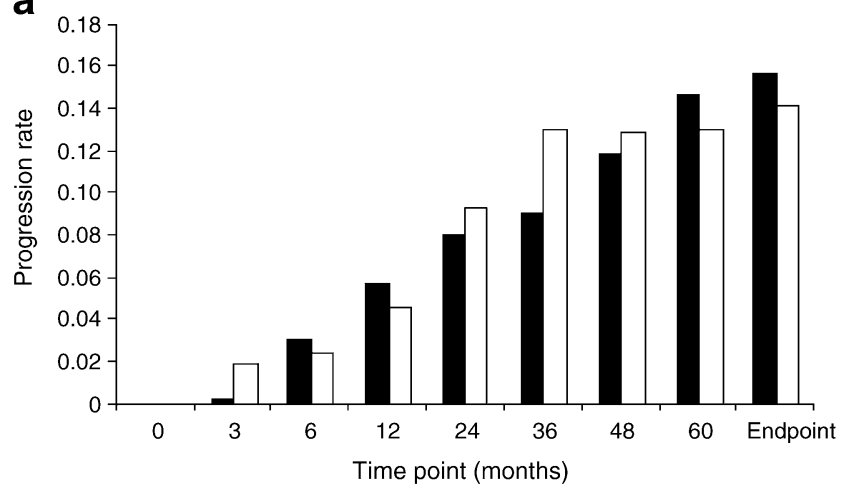

b

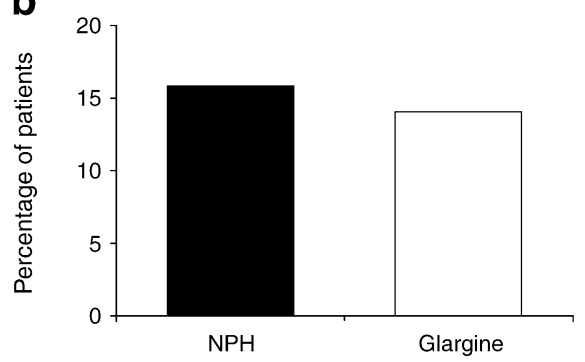

Fig. 3 Primary and secondary retinopathy outcomes following treatment with either twice-daily NPH insulin (black bars) or oncedaily insulin glargine (white bars; PP population). a Prevalence of three or more step progression on the ETDRS retinopathy severity scale during the course of the study. Percentage of patients calculated using the number of PP population as denominator. b Proportion of patients with three or more step progression on the ETDRS scale at endpoint. Percentage of patients calculated using the number of participants in the PP population as the denominator. There were 57/ $363(15.7 \%)$ of NPH insulin-treated patients and 53/374 (14.2\%) of insulin glargine-treated patients with three or more step progression on the ETDRS. The difference in progression rate between treatment groups was $-1.98(95 \% \mathrm{CI}-7.02,3.06)$ treated patients and $15.7 \%(57 / 363)$ of NPH insulin-treated patients in the PP population had three or more step progression in ETDRS score (Fig. 3b). The difference in the incidence of progression was $-1.98 \%$ (95\% CI $-7.02 \%$, $3.06 \%$ ) for insulin glargine vs NPH insulin, demonstrating non-inferiority of insulin glargine compared with NPH insulin. At endpoint, in approximately $25 \%$ of patients in each treatment group, retinopathy had progressed by two or more steps (ESM Fig. 1).

On analysis of the development of ophthalmic lesions, neither the proliferative diabetic retinopathy development rate nor the incidence of progression to clinically significant macular oedema were significantly different between treatment groups over 5 years in either the ITT or PP populations (Table 3 ).

Safety profile Body weight gain tended to be greater with $\mathrm{NPH}$ insulin than with insulin glargine, with a baseline to endpoint increase in mean body weight of $3.7 \mathrm{~kg}$ for insulin glargine and $4.8 \mathrm{~kg}$ for NPH insulin (ITT population; $p=$ 0.0505; ESM Fig. 2).

The rates of adverse events were similar for the two treatments (ESM Table 1). As shown in ESM Table 2, disparities between treatment groups for events with an incidence of at least 5\% in the insulin glargine group, with a difference in incidence by treatment group of at least $1 \%$, were not remarkable in any case. There was no observable trend for a difference in the incidence of serious adverse events, as well as adverse events leading to study withdrawal, and the overall incidence of adverse events leading to death was low and comparable between treatment groups (ESM Table 1).

There were minimal changes in mean blood pressure in both treatment groups from baseline to endpoint in the ITT population. For the insulin glargine and NPH insulin groups, LS mean change from baseline to endpoint systolic blood pressure was $+1.1 \pm 0.8$ and $+1.6 \pm 0.8 \mathrm{mmHg}$ and diastolic blood pressure was $-2.4 \pm 0.4$ and $-2.2 \pm 0.4 \mathrm{mmHg}$, respectively.

\section{Discussion}

This study was specifically designed to detect differences in the incidence of retinopathy progression by fundus photography over a 5 year period. To ensure the greatest possible objectivity of this assessment, retinopathy scoring was conducted at a single ophthalmologic centre, in a standardised fashion, by specially trained and certified graders who were masked to treatment. Throughout the study, changes in ETDRS scores in each group were remarkably similar, with no significant differences between treatment 
groups. Likewise, there were no significant differences in the number of patients with clinically significant macular oedema and proliferative diabetic retinopathy development between the insulin glargine and NPH insulin groups. Collectively, these results demonstrate that treatment of type 2 diabetes mellitus with insulin glargine over 5 years was not associated with an increase in progression of diabetic retinopathy, compared with NPH insulin treatment.

Because the primary objective of this study was to examine effects on diabetic retinopathy, and not to specifically evaluate intensive glycaemic lowering, similar levels of glycaemic control were sought by the treatment strategy, to minimise any confounding effect on the interpretation of the retinal findings. Despite this intent, a small difference in $\mathrm{HbA}_{1 \mathrm{c}}$ levels in favour of twice-daily $\mathrm{NPH}$ insulin $(7.6 \%$ vs $7.8 \% ; p=0.0053)$ was observed between the two treatments at endpoint. The statistical significance was probably detected because of the large sample size required for the retinopathy primary analysis. Furthermore, the upper bound of the $95 \% \mathrm{CI}$ for $\mathrm{HbA}_{1 \mathrm{c}}$ treatment effect $(0.35 \%)$ was lower than the non-inferiority margin of $0.4 \%$ commonly used to compare two glucoselowering treatments. Given that control of FPG was similar between the two groups, the lower $\mathrm{HbA}_{1 \mathrm{c}}$ levels in the $\mathrm{NPH}$ insulin arm of the study were presumably due to lower glucose levels during the day, likely related to the higher doses of the twice-daily NPH insulin regimen compared with once-daily insulin glargine, and perhaps to the higher percentage of patients combining prandial insulin with $\mathrm{NPH}$ insulin. Of note, in the exploratory analysis on the cohort of approximately one third of the study population who took basal insulin only, mean $\mathrm{HbA}_{1 \mathrm{c}}$ levels at any visit were nearly identical in both groups for most of the study. In any event, the presence of lower $\mathrm{HbA}_{1 \mathrm{c}}$ levels of $0.1 \%$ at baseline and $0.2 \%$ at study end in the NPH insulin arm strengthens the observation that, if different at all, the retinal changes were slightly less with insulin glargine than with NPH insulin treatment. Lending further support to this interpretation is the somewhat greater prevalence of retinopathy in the insulin glargine group at baseline, both in terms of medical history and of more severe ETDRS scores, which might predispose these patients to faster progression of diabetic retinopathy.

This is the longest controlled study ever reported using insulin glargine. It has demonstrated sustained glycaemic improvements and a reduced risk of severe hypoglycaemia compared with NPH insulin. Furthermore, the average weight gain was approximately 0.74 and $0.96 \mathrm{~kg} /$ year for insulin glargine and NPH insulin, respectively, over the 5 year study.

The lack of increase in progression of retinopathy seen with long-term insulin glargine treatment in this study is a point of discussion in terms of the hypothesis that the greater binding affinity of insulin glargine compared with NPH insulin for the IGF-1 receptor may lead to accelerated progression of retinopathy (a marker of mitogenicity), as suggested by some in vitro studies [23, 24]. It should be noted that the majority of in vitro and in vivo studies have shown that insulin glargine is not associated with increased mitogenic activity at physiological concentrations [25-28], and that mitogenicity is only seen in studies using cancer cell lines and when insulin is administered at supraphysiological concentrations $[24,26]$. There is further evidence against problematic glargine-induced signalling at the insulin receptor: insulin glargine dissociates rapidly from the receptor, in contrast to the mitogenic B10Asp insulin, which dissociates at a much slower rate [29].

The frequency of retinopathy progression observed in this study was similar to that previously reported in the UK Prospective Diabetes Study (UKPDS), a large, long-term, randomised trial of intensive treatment in patients with newly diagnosed type 2 diabetes mellitus [2, 4]. In a subset of UKPDS patients with adequate fundus photographs at both the baseline and 6 year visits (all treatment groups combined), progression of retinopathy by two or more steps on the ETDRS scale was observed in 467 of 1,919 patients $(24.3 \%)$, which is very similar to the 5 year two or more step progression observed in our patients (approximately $25 \%$ ). Caution is required when comparing these frequencies because of differences between the studies, in particular the side-by-side comparison of baseline and follow-up photographs used by the Wisconsin grading centre to confirm progressions of three or more steps, which may have reduced the frequency observed in our study. The recently diagnosed type 2 diabetes patients in the UKPDS and the patients in the present study (mean diabetes duration 10 years) also differed in terms of the presence of retinopathy at baseline (defined as at least one microaneurysm in at least one eye; $37 \%$ vs $61 \%$, respectively).

In summary, this long-term, adequately powered study robustly confirms that treatment with insulin glargine does not confer any greater risk of worsening of diabetic retinopathy than does NPH insulin treatment [18]. Moreover, it provides further new information regarding the long-term safety of insulin glargine compared with NPH insulin, beyond that of ophthalmic safety, demonstrating that similarly sustained improvements in glycaemic control with a lower risk of hypoglycaemia can be obtained with once-daily insulin glargine compared with twice-daily NPH insulin.

Acknowledgements This study was sponsored by sanofi-aventis. Editorial support was provided by N. Gingles through the global publications group of sanofi-aventis. We would like to thank all investigators and patients who participated in this study. Biostatistical analysis, based on the entire raw data set and evaluation of the 
study protocol and prespecified plan for data analysis, was provided by X. Guo (sanofi-aventis) and were independently confirmed by C. L. Yau of Tulane University. Data from this manuscript were presented as an oral presentation at the American Diabetes Association 2008 congress (San Francisco, CA, USA, 6-10 June 2008).

Duality of interest J. Rosenstock has received grants for research from and/or has been a consultant to Amylin, Boehringer-Ingelheim, BristolMyers Squibb, Centocor, Eli Lilly, Emisphere, GlaxoSmithKline, Johnson \& Johnson, MannKind, Merck, Novartis, Novo Nordisk, Pfizer, Roche, Sankyo, sanofi-aventis and Takeda. V. Fonseca has received research support (to Tulane University) with grants from GlaxoSmithKline, Novartis, Novo Nordisk, Takeda, Astra-Zeneca, Pfizer, sanofi-aventis, Eli Lilly, Daiichi-Sankyo, Novartis, the National Institutes of Health (NIH) and the American Diabetes Association (ADA), and honoraria for consulting and lectures from GlaxoSmithKline, Novartis, Takeda, Pfizer, sanofi-aventis and Eli Lilly. J. McGill has received grant support (to Washington University) from sanofi-aventis, Pfizer, Eli Lilly, Novo Nordisk, Novartis, GlaxoSmithKline, Elixir, Tolerx, Biodel, Mannkind, Takeda; served on advisory boards and speakers' bureaus for sanofiaventis and Novo Nordisk, and on speakers' bureaus for Eli Lilly, Merck, Novartis, Novo Nordisk, sanofi-aventis, Daiichi-Sankyo, Forest and GlaxoSmithKline; and has been a consultant/advisor for Merck, Novo Nordisk, Elixir, Mannkind, Amgen. I. Hramiak has received research grant support from Pfizer, sanofi-aventis, Novo Nordisk and Eli Lilly and has served on advisory boards for GlaxoSmithKline, Novo Nordisk, sanofi-aventis and Merck. J.-P. Hallé has received grants for research from and/or has been a consultant and/or on the speaker bureau of Bristol-Myers Squibb, ConjuChem, Bellus Health, Eli Lilly, GlaxoSmithKline, Merck Frosst, Novartis, Novo Nordisk, Pfizer, Roche, sanofi-aventis and Takeda. M. Riddle has received grants for research and/or honoraria for consulting or lectures from Amylin, Lilly, the Amylin-Lilly Alliance, Novo Nordisk, Pfizer, sanofi-aventis and Valeritas. P. Johnston is an employee of, and holds stock options from, sanofiaventis. M. Davis has received research support from sanofi-aventis.

Open Access This article is distributed under the terms of the Creative Commons Attribution Noncommercial License which permits any noncommercial use, distribution, and reproduction in any medium, provided the original author(s) and source are credited.

\section{References}

1. Diabetes Control and Complications Trial Research Group (1995) Effect of intensive therapy on the development and progression of diabetic nephropathy in the Diabetes Control and Complications Trial. The Diabetes Control and Complications (DCCT) Research Group. Kidney Int 47:1703-1720

2. Stratton IM, Kohner EM, Aldington SJ et al (2001) UKPDS 50: risk factors for incidence and progression of retinopathy in type II diabetes over 6 years from diagnosis. Diabetologia 44:156-163

3. Holman RR, Paul SK, Bethel MA, Matthews DR, Neil HA (2008) 10-Year follow-up of intensive glucose control in type 2 diabetes. N Engl J Med 359:1577-1589

4. UK Prospective Diabetes Study (UKPDS) Group (1998) Intensive blood-glucose control with sulphonylureas or insulin compared with conventional treatment and risk of complications in patients with type 2 diabetes (UKPDS 33). Lancet 352:837-853

5. Diabetes Control and Complications Trial Research Group (1993) The effect of intensive treatment of diabetes on the development and progression of long-term complications in insulin-dependent diabetes mellitus. N Engl J Med 329:977-986
6. Owens DR, Zinman B, Bolli GB (2001) Insulins today and beyond. Lancet 358:739-746

7. Rolla A (2008) Pharmacokinetic and pharmacodynamic advantages of insulin analogues and premixed insulin analogues over human insulins: impact on efficacy and safety. Am J Med 121:S9-S19

8. Peterson GE (2006) Intermediate and long-acting insulins: a review of NPH insulin, insulin glargine and insulin detemir. Curr Med Res Opin 22:2613-2619

9. Owens DR, Bolli GB (2008) Beyond the era of NPH insulin-longacting insulin analogs: chemistry, comparative pharmacology, and clinical application. Diabetes Technol Ther 10:333-349

10. Porcellati F, Rossetti P, Busciantella NR et al (2007) Comparison of pharmacokinetics and dynamics of the long-acting insulin analogs glargine and detemir at steady state in type 1 diabetes: a doubleblind, randomized, crossover study. Diabetes Care 30:2447-2452

11. Home PD, Rosskamp R, Forjanic-Klapproth J, Dressler A (2005) A randomized multicentre trial of insulin glargine compared with NPH insulin in people with type 1 diabetes. Diabetes Metab Res Rev 21:545-553

12. Massi-Benedetti M, Humburg E, Dressler A, Ziemen M (2003) A one-year, randomised, multicentre trial comparing insulin glargine with NPH insulin in combination with oral agents in patients with type 2 diabetes. Horm Metab Res 35:189-196

13. Ratner RE, Hirsch IB, Neifing JL, Garg SK, Mecca TE, Wilson CA (2000) Less hypoglycemia with insulin glargine in intensive insulin therapy for type 1 diabetes. U.S. Study Group of Insulin Glargine in Type 1 Diabetes. Diabetes Care 23:639-643

14. Rosenstock J, Schwartz SL, Clark CM Jr, Park GD, Donley DW, Edwards MB (2001) Basal insulin therapy in type 2 diabetes: 28-week comparison of insulin glargine (HOE 901) and NPH insulin. Diabetes Care 24:631-636

15. Yki-Jarvinen H, Dressler A, Ziemen M (2000) Less nocturnal hypoglycemia and better post-dinner glucose control with bedtime insulin glargine compared with bedtime NPH insulin during insulin combination therapy in type 2 diabetes. HOE 901/3002 Study Group. Diabetes Care 23:1130-1136

16. Mullins P, Sharplin P, Yki-Jarvinen H, Riddle MC, Haring HU (2007) Negative binomial meta-regression analysis of combined glycosylated hemoglobin and hypoglycemia outcomes across eleven phase III and IV studies of insulin glargine compared with neutral protamine Hagedorn insulin in type 1 and type 2 diabetes mellitus. Clin Ther 29:1607-1619

17. Riddle MC, Rosenstock J, Gerich J (2003) The treat-to-target trial: randomized addition of glargine or human NPH insulin to oral therapy of type 2 diabetic patients. Diabetes Care 26:3080-3086

18. Davis MD, Beck RW, Home PD, Sandow J, Ferris FL (2007) Early retinopathy progression in four randomized trials comparing insulin glargine and NPH [corrected] insulin. Exp Clin Endocrinol Diabetes 115:240-243

19. Early Treatment Diabetic Retinopathy Research Group (1991) Grading diabetic retinopathy from stereoscopic color fundus photographs - an extension of the modified Airlie House classification. ETDRS report number 10. Early Treatment Diabetic Retinopathy Study Research Group. Ophthalmology 98:786-806

20. Early Treatment Diabetic Retinopathy Research Group (1985) Photocoagulation for diabetic macular edema. Early Treatment Diabetic Retinopathy Study report number 1. Arch Ophthalmol 103:1796-1806

21. Early Treatment Diabetic Retinopathy Study Research Group (1991) Fundus photographic risk factors for progression of diabetic retinopathy. ETDRS report number 12. Ophthalmology 98:823-833

22. Writing Team for the Diabetes Control and Complications Trial/ Epidemiology of Diabetes Interventions and Complications Research Group (2002) Effect of intensive therapy on the microvascular complications of type 1 diabetes mellitus. JAMA 287:2563-2569 
23. MacDonald PE, Joseph JW, Rorsman P (2005) Glucose-sensing mechanisms in pancreatic beta-cells. Philos Trans R Soc Lond B Biol Sci 360:2211-2225

24. Mayer D, Shukla A, Enzmann H (2008) Proliferative effects of insulin analogues on mammary epithelial cells. Arch Physiol Biochem 114:38-44

25. Staiger K, Hennige AM, Staiger H, Haring HU, Kellerer M (2007) Comparison of the mitogenic potency of regular human insulin and its analogue glargine in normal and transformed human breast epithelial cells. Horm Metab Res 39:65-67

26. Bähr M, Kolter T, Seipke G, Eckel J (1997) Growth promoting and metabolic activity of the human insulin analogue [Gly ${ }^{\mathrm{A} 21}$,
$\operatorname{Arg}^{\mathrm{B} 31}, \operatorname{ArgB}^{32}$ ]insulin (HOE 901) in muscle cells. Eur $\mathrm{J}$ Pharmacol 320:259-265

27. Chisalita SI, Arnqvist HJ (2004) Insulin-like growth factor I receptors are more abundant than insulin receptors in human micro- and macrovascular endothelial cells. Am J Physiol Endocrinol Metab 286:E896-E901

28. Le Roith D (2007) Insulin glargine and receptor-mediated signalling: clinical implications in treating type 2 diabetes. Diabetes Metab Res Rev 23:593-599

29. Kurtzhals P, Schaffer L, Sorensen A et al (2000) Correlations of receptor binding and metabolic and mitogenic potencies of insulin analogs designed for clinical use. Diabetes 49:999-1005 